\title{
Después de los 50 ¿qué?
}

\author{
Gonzalo Delamaza \\ Director POLIS, Revista Latinoamericana, Universidad de los Lagos, \\ Santiago, Chile. \\ Email: gonzalo.delamaza@ulagos.cl
}

La memoria de los 50 años transcurridos desde la encrucijada de 1968 está llena de claroscuros para quienes buscan transformaciones que humanicen la humanidad, que sustenten el desarrollo y acrecienten el buen vivir de todas y todos. Por una parte se han impuesto alternativas excluyentes en el campo económico, como la concentración de la riqueza, la financiarización de la economía y la destrucción del trabajo. Desde ese punto de vista podemos decir que los ideales de 1968 han fracasado, tal como fracasaron ese año en Praga bajo los tanques del Pacto de Varsovia, en México bajo el fuego de las ametralladoras en Tlatelolcoy en los Estados Unidos con los asesinatos a tiros de los líderes progresistas de la época. Luego vino la ola neoliberal, ensayada en Chile y luego replicada en muchos lugares, con desastrosas consecuencias. Y más tarde la ola globalizadora hegemonizada por el capital financiero, la economía especulativa y la intensificación extractiva que ha puesto en riesgo tanto bienes naturales como aspectos de la vida social fundamentales para el presente y futuro de nuestro planeta. Todo ello acompañado de un desarrollo tecnológico inimaginado que permitiría contar con buenas respuestas para todas y todos. Pero que no lo logra.

Pero la emergencia social y política del '68 no ha cesado: la pluralización de los actores sociales expresados en los "nuevos movimientos sociales”, la politización de las causas de la vida cotidiana que vino a complementar y brindar alternativas a la crisis de los "grandes relatos" después de 1989, son muestra de ello. En nuestra región latinoamericana podemos verlo en la emergencia del movimiento indígena, antes invisibilizado y negado por la dominación secular y el desarrollismo unilateral. En la generalización de la democracia política luego de décadas de dictaduras militares y autoritarismos de todo orden. En la defensa de los derechos humanos como una causa común de los pueblos. La enumeración sería larga y deriesgosa interpretación.

En el momento presente hemos pasado una vez más de la esperanza a la confusión. Tuvimos un período auspicioso -al menos en Sudaméricadonde avanzaban simultáneamente las nuevas propuestas del "socialismo del Siglo XXI” en Bolivia, Ecuador y Venezuela y las reformas progresivas en países como Brasil, Argentina, Uruguay e hasta en Chile. Incluso Perú lograba recuperarse del autoritarismo de Fujimori y la guerra interna desatada por Sendero Luminoso. Pero hoy el panorama es diferente: las alternativas progresistas se muestran agotadas, sin haber enfrentado realmente los 
desafíos de un "otro desarrollo". La redistribución parcial de los ingresos de recursos naturales -con su enorme carga de deterioro ambiental y falta de sostenibilidad- no fue duradera ni brinda autonomía. La personalización de los liderazgos fue sustituyendo a la construcción de alternativas colectivas de transformación política: esperable en un gobierno de origen militar como Venezuela pero no de uno surgido “desde abajo" como Brasil o de una revolución triunfante como en Nicaragua. Pero, peor aún, la corrupción política a manos de los grandes capitales, la moneda corriente de nuestra política conservadora, se hizo carne también en la política progresista. Y frente a eso aún no hay respuesta. Odebrecht en toda la región; SQM (del yerno de Pinochet) en Chile; los narcodólares en muchos países y suma y sigue. Tampoco la hay a la violencia social se acrecienta en todo el itsmo centroamericano, en las fronteras mexicanas, en Venezuela y su crisis de la seguridad (que se suma a otras crisis) y sobre todo Brasil. Ni a las crisis migratorias, que no son patrimonio de la Unión Europea, pues también las vivimos en la región.

En el campo académico y en particular de las ciencias sociales también el período ha sido complejo. Se reformaron y modernizaron las universidades, se ampliaron las temáticas e incrementaron las y los investigadores. Se han desarrollado perspectivas intelectuales y epistemológicas renovadas valorando la producción local de conocimiento, la vinculación con los sujetos sociales, el diálogo sur - sur, las búsquedas inter y trans-disciplinarias, se ha complejizado la relación entre teoría y práctica y se han multiplicado las perspectivas teóricas mucho más allá de la dicotomía modernización /dependencia o reforma/revolución de los lejanos 60 y 70.

Pero al mismo tiempo la hegemonía sobre la producción de conocimiento se ha ido consolidando en torno al productivismo tecnocrático (por llamarlo de algún modo), aquella modalidad que renuncia a paradigmas propios de las ciencias sociales y humanas y se suma al cientificismo universal, que renuncia a la teoría, que singulariza el método y uniforma la circulación en un mercado académico en manos privadas. Vale decir, las condiciones de producción de las ciencias sociales se han estrechado, encorsetando y distorsionando cada vez más la generación de conocimiento apropiado, válido y pertinente para nuestras sociedades y sus desafíos. No es que domine realmente un pensamiento único, como quizás ocurrió a fines de los noventa, donde se llegó a fantasear con el "fin de la historia". Ahora lo que domina es la estandarización de los procedimientos, los rankings y los estándares procesables por herramientas de cómputo. Habiéndose prácticamente vaciado de contenido, especialmente luego de la crisis de 2009, los modelos hegemónicos de conocimiento y gestión de lo público siguen aún operando a través de sus instrumentos, pero sin validez efectiva. Subsisten los negocios que se transmiten a través de operaciones cada vez más grandes y globalizadas, pero ya no hay un proyecto detrás. No es de extrañar si las propuestas de desarrollo y orden social dominantes hacen agua hace ya tiempo: el ascenso del populismo de derecha en varios países, las guerras en medio oriente con su secuela de terrorismo y desplazamiento de poblaciones, el aislacionismo de las grandes potencias, la desarticulación de la 
Unión Europea, la falta de respuestas eficaces del sistema internacional frente a los fenómenos de cambio climático, crisis humanitarias, la crisis de la social democracia, en fin todos son síntomas de un cambio de ciclo que no sabemos bien donde apunta.

Frente a este panorama las respuestas son más complejas y los desafíos del conocimiento se agigantan. La utopía de la liberación, que explotó en 1968,tuvo su mayor efecto en fundamentar la necesidad del pensamiento crítico y la deconstrucción del orden establecido, que se presenta naturalizado. Eso significó un enorme aporte, con gran repercusión en América Latina, desde la educación liberadora de Paulo Freire a los postuladosde un saber decolonial.Pero sin duda ello no bastó ni basta. No basta para abordar la construcción de los nuevos órdenes deseados en la complejidad que involucran. Si la meta es emancipatoria, se requiere no sólo del pensamiento crítico de las estructuras existentes. Hay que daruna vuelta más larga para pensar alternativas viables, con sentido de futuro en un mundo orientado al presentismo, incluyentes donde crece la exclusión, colectivas donde predomina el individualismo y diversas aunque no dispersas. Y que dialoguen con la experiencia política efectiva, aportando en un sentido propositivo así como retroalimentándose desde la práctica, siempre más prosaica y menos épica. Nada fácil. Pero de otro modo se arriesga sobrevalorar el papel de las y los intelectuales como guardianes autodesignados de la conciencia crítica pero impotentes ante las complejidades de la transformación efectiva de la realidad que critican.

Así entonces, la proyección de lo que se abrió paso en 1968 -el realismo de querer lo imposible- siempre está actualizándose, no se congela en las cómodas verdades ya descubiertas, siempre está por hacer. El diálogo y la deliberación siguen siendo las herramientas de quienes trabajamos en la producción y circulación del conocimiento orientado a un mejor vivir. Hoy día esa tarea se ha vuelto más difícil. No por la disponibilidad de medios, que la tecnología ha vuelto cercanos, baratos y han posibilitado la multiplicidad de voces. Pero ¿̇sobre qué bases fundar los diálogos y la deliberación? ¿Sobre los tópicos impuestos por los medios de comunicación cada vez más concentrados en el mundo? ¿A partir de la postverdad y las campañas de desinformación a través de las redes sociales? ¿Cómo fortalecer el papel a la vez humilde y decisivo del pensamiento autónomo y la ciencia social bien hecha?

POLIS, Revista Latinoamericana entiende el desafío como uno que combine permanencia y continuidad luego de sus primeros 50 números, con apertura y exploración de nuevos rumbos para la publicación en ciencias sociales y humanas en la región. El primer compromiso sigue siendo el de publicar investigación rigurosa, no sujeta a cánones disciplinarios únicos, sino abierta a la multiplicidad en lo teórico y lo metodológico. Al mismo tiempo queremos seguir abonando saber en temas relevantes para nuevos horizontes de transformación y desarrollo. Dar espacio a lo no suficientemente tratado por los enfoques tradicionales. También nos importa sostener el diálogo plural en las ciencias sociales, fortaleciendo especialmente la 
circulación de conocimiento en y desde América Latina. Buscamos de ese modo equilibrar la peligrosa tendencia actual de reconvertir todo el conocimiento a un idioma extranjero y a un formato estandarizado. Las herramientas de comunicación actuales nos permiten el diálogo verdaderamente global, mucho más allá de lo que nunca imaginamos en el pasado y las hemos aprovechado multiplicando nuestra presencia en el mundo. Pero al mismo tiempo estimulamos la lectoría y debate en nuestro contexto sobre nuestros asuntos y problemas. Ello no se circunscribe únicamente a los científicos, sino que fomenta también el necesario diálogo social. Tampoco es un esfuerzo en solitario, por ello nos hemos hecho parte de las iniciativas de vinculación entre publicaciones académicas, que tendrá un momento significativo en el Foro SCIELO 20 años en Sao Paulo en noviembre 2018. Por último queremos seguir incrementando nuestras exigencias de calidad y reconocimiento como instrumento de difusión del pensamiento social latinoamericano en tiempos globales. Esperamos lograrlo durante los próximos 50 números de nuestra publicación. 